ARTIGOS - ARTICLES

\title{
Moral religiosa, economia política e bem comum
}

Daniel de Lara Oliveira ${ }^{1}$

Universidade de São Paulo

daniel.oliveira@alumni.usp.br

Como citar este artigo: OLIVEIRA, Daniel de Lara. "Moral religiosa, economia política e bem comum", Intelligere, Revista de História Intelectual, $\mathrm{n}^{\circ} 11$, pp. 22-51. 2021. Disponível em <http://revistas.usp.br/revistaintelligere>. Acesso $\mathrm{em} \mathrm{dd} / \mathrm{mm} /$ aaaa:

Resumo: $\mathrm{O}$ artigo toma para análise aspectos da visão de mundo expressa na obra de José da Silva Lisboa, em especial a partir daquela intitulada Estudos do Bem Comum, e assim dirige atenções à relação ali estabelecida entre moral religiosa e economia política, destacando a importância dos conceitos universais, apreendidos junto à filosofia natural, na construção de uma dada cosmologia. A partir de então, o presente texto identifica e busca compreender potencialidades e limites de tais universais nas análises e projeções tecidas por Silva Lisboa acerca da característica escravista da sociedade brasileira das primeiras décadas do século XIX, concluindo acerca da necessidade de um processo histórico que supere a conjuntura do escravismo e confira a legitimidade dos universais que compunham a visão de mundo.

Palavras-chave: José da Silva Lisboa. História Intelectual. Economia Política. Adam Smith.

\section{Religious moral, political economy and common good}

Abstract: This article aims at analyzing the worldview expressed in the work of José da Silva Lisboa, particularly from the one entitled "Estudos do Bem Comum", thereby driving its focus to the relation established between the religious moral and the political economy, highlighting the importance of the

1 Daniel de Lara Oliveira é Doutor em História pela Universidade de São Paulo. Analisou aspectos da filosofia natural e da cultura ilustrada na cosmologia expressa por José da Silva Lisboa, após pesquisar durante o mestrado questões relacionadas ao newtonianismo na obra de Luís António Verney. Atualmente, leciona na Educação Básica.

Curriculo Lattes: http://buscatextual.cnpq.br/buscatextual/visualizacv.do?id=K4248859U7 
universal concepts, learned with the natural philosophy, in the construction of a given cosmology. From this point, the present text identifies and seeks to understand potentialities and limits of such universals in the analyses and projections woven by Silva Lisboa concerning the enslaving characteristic of the Brazilian society from the first decades of the XIX century, coming to a conclusion about the need of a historical process able to overcome the scenario of the slavery and bring legitimacy of the universals that composed the worldview.

Keywords: José da Silva Lisboa. Intellectual History. Political Economy. Adam Smith.

Publicada pela Imprensa Régia entre 1819 e 1820, Estudos do bem comum e economia politica ou ciência das leis naturais e civis de animar e dirigir a geral indústria e promover a riqueza e prosperidade do Estado, de autoria de José da Silva Lisboa, foi tida como obra voltada aos estudos da economia política, então muito em voga nos circuitos intelectuais do período. No entanto, se este é o problema que salta aos olhos do leitor de modo mais explícito, também é possível considerála uma obra voltada a outras temáticas, a exemplo da moral, conforme o próprio autor sugere. Por sua vez, este texto tomará para análise Estudos do bem comum e projetará questões acerca das concepções de Silva Lisboa sobre a formação social brasileira, naquele efervescente contexto que antecedeu a independência política brasileira.

Aqui será considerada a hipótese de que os elementos da filosofia natural presentes na cosmovisão de Silva Lisboa possibilitaram ao autor uma aproximação entre a moral religiosa e a economia política, a fim de promover as condições necessárias ao bem comum. A sociedade almejada por Silva Lisboa seria alcançada segundo a orientação dos preceitos da economia política, cuja aplicação deveria ser condizente e mesmo submetida a uma dada moral religiosa. A aproximação entre essas áreas do saber ele pretendia ter alcançado através de elementos teóricos e conceituais encontrados na filosofia natural, os quais ocupavam lugar central em sua visão de mundo. A projeção dos conceitos de ordem universal sobre particularismos da sociedade brasileira levou Silva Lisboa a paradoxos que este artigo pretende identificar e explorar em alguma medida. 
Estudos do bem comum também reflete a passagem de Silva Lisboa pela Universidade de Coimbra. Luso-brasileiro natural de Salvador, capitania da Bahia, ali regressou para assumir cargos como os de ouvidor, professor régio e deputado da Mesa de Inspeção da Agricultura e do Comércio, quando em 1808 acompanhou a Corte portuguesa rumo à Baía de Guanabara. Já no Rio de Janeiro, foi nomeado diretor e censor da Impressão Régia e deputado da Junta do Comércio. Também atuou de modo intenso e frequente na imprensa, na política e enquanto autor de uma volumosa obra votada à diversificada temática. Em Estudos do bem comum reside um esforço de síntese de suas leituras e experiência, como também um apelo de orientação moral àquela nação rumo a emancipação política; esforços que tiveram continuidade durante e após o processo de independência.

Acerca dos posicionamentos em relação à atuação política e à obra de Silva Lisboa, em meio à farta bibliografia é possível citar as menções de Afonso Arinos, que chamando-o pelo título recebido em 1826, lembra que o Visconde de Cairu desde há muito vem sendo alvo do interesse de pesquisadores, cujo resultado de suas respectivas análises geraram críticas para cima e para baixo, muitas vezes marcadas pelo exagero. Por um lado, segundo Tristão Ataíde, Cairu fora considerado alto símbolo da cultura nacional; já o renomado Sérgio Buarque de Holanda, a dizer ao modo de Afonso Arinos, negou a Cairu pão e água (cf. FRANCO, 1947, p. 87).

A obra em questão, Estudos do bem comum, pode certamente ser colocada entre os trabalhos de Silva Lisboa que possibilitaram conclusões bastante diferenciadas, talvez em oposição extremada. Os anos anteriores à publicação dessa obra são justamente aqueles que antecederam a independência política do Brasil. Ao se tomar Estudos do bem comum como principal objeto das análises a serem realizadas neste momento, também é ponto de partida o pressuposto, já de certo modo indicado pela historiografia, de que é possível identificar ali indícios de uma dada concepção sobre aquela sociedade. Indícios suficientes para o enriquecimento do conhecimento histórico acerca do ideário daquele contexto, uma melhor compreensão dos projetos elaborados para aquela futura nação já repleta de problemas de enorme complexidade que de modo direto ou indireto foram mais uma vez tratados por Silva Lisboa. 
Relacionar Estudos do bem comum à temática da formação social, admitese, não consta entre as possibilidades mais imediatas oferecidas pela obra, no entanto, tendo a visão de mundo mais geral do autor como interesse deste artigo foi possível sim perguntar por questões dessa ordem. Afinal, a ideia de compreender a visão mais geral ou a cosmologia de Silva Lisboa passa pela investigação de suas concepções a respeito da sociedade, e pode apresentar resultados satisfatórios na medida em que tal tarefa pretende ser realizada a partir de leituras atentas ao cruzamento de áreas do saber que, se hoje encontram-se bem delimitadas, naquele contexto e mediante a visão do próprio Silva Lisboa não eram vistas assim.

Em meio a problemas ligados à economia política, Silva Lisboa destaca outra face da mesma obra, conduzindo o leitor a questões acerca da moral e a partir das quais, muitas vezes de modo indireto ou mesmo difuso, expõe suas concepções a respeito da sociedade brasileira. Já nas páginas iniciais, o autor aponta a problemática da moral entre suas preocupações. Como é típico em suas análises, Silva Lisboa salta de um comentário introdutório, que ao leitor atual pode parecer dotado de um espírito prático, para outro um tanto especulativo, de ordem moral, religiosa ou mesmo metafísica. Alerta o leitor a respeito do teor e objetivo da obra que está prestes a iniciar.

\footnotetext{
Não se espere que fatigue o público sugerindo planos de visionária prosperidade, que o Sistema do Mundo visível não admite, e ainda menos à vista do evidentemente decaído estado da constituição da humanidade; nem que iluda aos aspirantes a fortunas com esperanças de opulência sem indústria honesta ativa, e bem dirigida, e ainda menos com generalidade e igualdade nos objetos de gozo não essenciais à vida natural e civil (LISBOA, 1819, PREFÁCIO).
}

A condição humana a que faz menção o autor é fundamentada na concepção cristã acerca do pecado original, a qual ele utiliza junto a observações de cunho prático, descartando aspirações por fortunas e por uma prosperidade visionária, distante das possibilidades materiais que o mundo sensível permitiria admitir. Silva Lisboa discorrerá a respeito das riquezas disponíveis e sobre aquelas a serem alcançadas pelo Brasil, mas alerta desde os primeiros movimentos de seu texto sobre as condições a partir das quais essa riqueza será almejada. A investigação sobre tais condições mistura, em um único conjunto de observações e argumentos, preocupações materiais, 
religiosas ou mesmo metafísicas, para então desembocar em uma dada ideia a respeito da vida civil, ou seja, em aspirações ligadas ao modelo de organização social, econômica e política que espera para aquela nação, às vésperas de sua independência política.

Nesse imbricado conjunto de concepções, o problema da moral, que na obra divide espaço com farta diversidade temática abordada pelo autor, já havia sido mencionado em seus parágrafos anteriores. Mais adiante, surge de modo literal e reitera a possibilidade de que esta análise pudesse destacá-lo. Ao mencionar a importância da escola inglesa, formada por nomes como Adam Smith, Thomas Malthus e David Ricardo, cuja citações, embora acompanhadas quase sempre de uma leitura crítica, são recorrentes ao longo de toda a obra, Silva Lisboa começa a expor sua visão de mundo, a partir da qual passa a discorrer acerca do funcionamento da ordem social.

\footnotetext{
Todos estes insignes mestres fazem ver, que, na ordem social nada é vago e arbitrário e tudo depende de Leis constituídas pela Inteligência Infinita que ligou o físico ao moral, e segurou a observância das mesmas Leis por imutáveis sanções de miséria ou felicidade, vida ou morte, dos indivíduos ou Estados (LISBOA, 1819, PREFÁCIO).
}

Ao autor, o físico e o moral estão associados segundo a leitura que faz dos mestres em que se apoia. Sua visão geral de mundo concebe uma cosmologia na qual uma Inteligência Infinita imprimiu no mundo leis responsáveis por relacionar aspectos, à primeira vista tão díspares, mas cuja relação influi diretamente no sucesso dos indivíduos e mesmo dos Estados. Desde o primeiro capítulo, a abrir a extensa primeira parte de Estudos do bem comum, Silva Lisboa explicita sua preocupação em compor análise e argumentação a partir de uma economia política que pretende ser generalizante, dotada de princípios razoáveis, cujo conhecimento é necessário à condução do desenvolvimento, necessário à identificação e prosperidade da riqueza da nação.

Segundo sua cosmologia, a economia política se apresenta ao autor como uma possibilidade de síntese explicativa. Tal ciência orienta seu entendimento e, mediante as concepções que ali encontra, a moral atua como mais um determinante, um meio necessário para ao menos se aproximar da perfectibilidade social que está sendo almejada, sem a qual a própria riqueza 
estaria comprometida. Assim, o problema da riqueza da nação passa a todo momento por questões acerca da moral, rumo a uma determinada ordem social. Abaixo, é possível notar que Silva Lisboa demonstra conhecer de modo bastante razoável o contexto intelectual a que se refere e com o qual dialoga. Se anteriormente citou autores de reconhecida propriedade em economia política, em seguida, aponta algumas das principais matrizes da teoria e método que compartilha e onde residem as origens epistemológicas dessa mesma escola de pensamento. Tais apontamentos e comentários mais uma vez confirmam não somente a razoabilidade, mas a necessidade de se projetar sobre seus textos as questões que a presente análise pretendeu explorar.

\begin{abstract}
Agora convém que nesta parte do Novo Mundo não se estime somente a Geórgia do Território, mas também a Geórgia do Espirito, conforme a frase e lição de Bacon, que, com o seu Novo Órgão das Ciências, deu o mais espiritual sopro aos estudos úteis das nações modernas, ensinando o seu método analítico de achar a verdade, por observações e experiências de fatos que estão aos olhos do mundo, para deles se deduzirem os sólidos Princípios e Sistemas que regulem a Sociedade (SILVA LISBOA, 1819, p. 07).
\end{abstract}

A menção à obra de Francis Bacon e ao método analítico conduz o leitor à escola empirista inglesa, cujo nome de maior expressão é o de Isaac Newton. Ainda que sem considerar aqui as específicas diferenças epistemológicas e conceituais entre tais propostas metodológicas, o que fora chamado de resolução e composição por Bacon e análise e síntese por Newton, é tomado por Silva Lisboa a fim de destacar sua preocupação em adotar uma dada postura epistemológica, o empirismo, nos estudos acerca da economia política e do próprio bem comum que então se colocava a apresentar. Desta feita, observação e a experiência, a partir de fatos que estão aos olhos do mundo, permitiram a dedução, a composição, a síntese, dos princípios e sistemas reguladores da sociedade. A passagem acima é mais uma explícita alusão ao paradigma newtoniano, tido como matriz epistemológica de muitos mentores de Silva Lisboa em economia política, a exemplo do próprio Adam Smith.

Se a filosofia natural conferiu uma postura mais crítica e razoável à produção do saber, como reconhece Silva Lisboa, a moral surge para apontar a melhor direção de seu emprego: o bem da humanidade, o bem de todas as nações. Assim, é necessário questionar sobre as condições em que problemas acerca da moral estariam inseridos nessa cosmologia. A partir do subtítulo Necessidade e importancia dos estudos do bem comum, Silva Lisboa sinaliza essa relação 
entre o conhecimento e a moral. Ainda que não dotado de clareza suficiente, abre o capítulo com apelos dessa natureza, além de adiantar sua declarada aversão à revolução social enquanto uma de suas maiores preocupações. A partir de uma cosmologia que reúne aspectos da filosofia natural, da moral e tantos outros elementos, discorrerá sobre a economia política, mirando uma determinada ordem social, dotada de elementos conservadores cuja identificação e análise muitas vezes não parece comportar a simplicidade imediata, por tantas vezes recorrente na bibliografia a respeito do autor e sua obra.

O terrível choque que a Europa e América sofreram no fim do século passado, e que abalou os fundamentos da esperança, da 'Perfectibilidade Social', atrasando os estudos úteis para esse destino, e até sugerindo indiferença e desconfiança ao adiantamento da inteligência humana, ainda nos objetos de imediato interesse à vida e paz geral, impossibilitou dirigir-se a atenção dos estudiosos para inquirição dos eficazes meios da prosperidade pública, fundados nas Leis do Sistema Cosmológico, de cujo conhecimento deve resultar o maior bem possível da Humanidade, e de qualquer Nação (SILVA LISBOA, 1819, p. 6).

Assim, Estudos do bem comum trata, de modo conciliatório e reciprocamente determinante, os problemas acerca da riqueza da nação e a necessidade de evitar a revolta social. Referindo-se às Revoluções Francesa e Americana como interrupções dos possíveis avanços que o conhecimento deveria conferir ao destino dos povos, Silva Lisboa chama a atenção para a possível prosperidade pública que esse mesmo saber poderia conferir às nações, uma vez que a partir dele seria possível identificar leis de um sistema cosmológico, para melhor buscar a perfectibilidade social, ainda que esta última expressão encontre-se entre aspas.

O bem comum deve ser buscado a partir da economia política, conhecimento proveniente da Ilustração, sob reconhecida influência do paradigma da filosofia natural de matriz inglesa, mais propriamente newtoniana, a compor uma cosmologia na qual também estiveram inseridos como determinantes os elementos morais e religiosos, a formular uma argumentação cuja lógica interna não deveria perder de vista a preocupação em evitar revoluções sociais. Tais são as condições em que a moral esteve inserida em sua cosmologia, ligada a suas preocupações de cunho social. Para Silva 
Lisboa, a moral possuía sobretudo a função educadora, muitas vezes dotada de certo otimismo e positividade.

É notório e já muito analisado o impacto que as revoluções mencionadas por Silva Lisboa imprimiram sobre a política, a economia e mesmo sobre o imaginário do período histórico em que estiveram inseridas e de períodos ainda vindouros ${ }^{2}$. É de igual conhecimento que tal impacto assumiu feições características a cada contexto em que se dava. Ainda que em franco diálogo com escolas de pensamento europeias e a compartilhar conceitos e métodos tidos por ele como universais, Silva Lisboa produziu suas análises tendo em vista especificidades do contexto em que viveu; seu interesse maior residia na situação do Brasil, então ainda ligado ao Império Português. Nesse cruzamento entre o geral e o particular, se viu diante de paradoxos que sua obra de pensamento não pode evitar.

O impacto das revoluções está entre as preocupações centrais de Silva Lisboa. O bem comum deve ser alcançado sem revolução social, bem como a fim de evitar a revolução social. Sob seu julgo, bem comum e revolução não condizem. A sociedade deve ser educada para o espírito antirrevolucionário. Como há pouco foi afirmado, a leitura atenta da obra Silva Lisboa permite identificar ali a missão educadora da moral. Neste ponto reside uma das mais importantes funções da moral, mas nem por isso torna-se tarefa simples classificar Silva Lisboa como um mero conservador. Sua postura avessa à revolução não o levou a um conservadorismo simplista. Se por um lado pode ser difícil compreender a fundo suas concepções, por outro é certamente mais promissora tal compreensão do que estabelecer classificações imprecisas, porque apressadas.

Mediante tais condições apresentadas pelo próprio autor, a partir de então estará de certo modo isolada a relação entre a moral e a riqueza da nação, para assim buscar alguma compreensão histórica mais apurada sobre o que concebia Silva Lisboa acerca da sociedade brasileira. Para isso, cabe destacar eixos temáticos, a partir dos quais a relação entre moral e riqueza da

\footnotetext{
2 O tema da repercussão da Revolução Francesa é muito recorrente e de abordagem temática muito variada. Em se tratando de Brasil e América Latina, cabe citar a obra $A$ Revolução Francesa e seu Impacto na América Latina, que reúne artigos de diversificada temática e orientação, sob organização do professor Osvaldo Coggiola (cf. COGGIOLA, 1990).
} 
nação conduzirá esta análise às concepções de Silva Lisboa a respeito da sociedade brasileira.

\section{Discursos de síntese. Filosofia natural, moral e religião}

De modo introdutório, já foi possível notar em Estudos do bem comum a filiação de seu autor a uma postura epistemológica tributária do empirismo inglês, seu apelo à escola clássica, em especial, Smith e Malthus, atuando em conjunto com uma visão de mundo marcada por diversificadas concepções, em especial aquelas ligadas à sua religiosidade cristã, elemento determinante na condução de toda sua obra. Segundo o entendimento de Silva Lisboa, como já apontado, a condição humana estava marcada, antes de mais nada, pela concepção cristã do pecado original. Ainda que promissora e adotada com espírito de otimismo, a economia política deveria instruir a construção da riqueza nacional a partir dessa situação predeterminada, conforme a orientação da religiosidade cristã e católica a que se filiava Silva Lisboa, impondo assim a necessidade de uma moral de destacada finalidade educadora.

Sua cosmologia pretendia ser capaz de conciliar tais elementos à primeira vista tão díspares. Tal conciliação ou mesmo coerência interna só foi possível a partir da filosofia natural compartilhada por Silva Lisboa, a qual comportava conceitos tidos como de caráter universal apropriados junto à filosofia natural mais comum entre o pensamento ilustrado, evitando incoerências junto à sua religiosidade cristã. Assim, adotara a economia política, a ciência que encaminharia discussões acerca da riqueza nacional, sem com isso afastar-se da moral de cunho cristão. A sociedade pensada e almejada por Silva Lisboa deveria estar delimitada por esses moldes.

Avançando a análise segundo a temática sugerida, encontramos em Estudos do bem comum passagens onde mais uma vez é possível notar a relação entre o problema da riqueza da nação e a moral cristã a partir de um arranjo conceitual retirado da filosofia da natureza. Já no prefácio da obra, Silva Lisboa reconhece na economia política o caráter de ciência, e atribui à mesma um destino transcendente. No primeiro capítulo, intitulado Necessidade e importância dos Estudos do Bem Comum, a mesma economia política é novamente apresentada a partir de sua capacidade de transitar entre saberes diversos. 
... é inquestionável a mútua dependência com que se ligam todos os ramos das ciências; contudo é não menos certo, que alguns são de tão fundamental interesse, que, sem os seus estudos, nenhum dos outros pode prosperar, e nem ainda consideravelmente existir. Este caráter, depois dos estudos da Religião Cristã, com justiça pertence aos de Economia Política (LISBOA, 1819, p. 06).

O autor sugere que a economia política é uma ciência de síntese e só não mais imprescindível que a própria religião cristã, pois capaz de relacionar os saberes diversos, incluindo a literatura, segundo ele muitas vezes utilizada com exagero, mas necessária à ciência. Contrariando interpretações que atribuem a Silva Lisboa radical preponderância do trabalho intelectual sobre os afazeres manuais, de ordem prática, segue sua explanação reconhecendo a necessidade de que as artes mecânicas tenham gerado alguma riqueza material, para que então alguns pudessem se dedicar ao estudo das leis e obras do Criador. Para corroborar sua tese, passa a citar fontes de natureza diversa. Faz menção ao Eclesiastes, mas lembra também de frases atribuídas a Alexandro Magno, por meio de escritos deixados por um dos primeiros donatários da colônia: primeiro é enriquecer, e depois filosofar (cf. LISBOA, 1819, p. 07).

As citações de mais variada ordem seguem em frente; Silva Lisboa levará ao leitor fragmentos da obra de Montesquieu, para então chegar aos pensadores ingleses e concluir retomando seu cristianismo. Em sua cosmologia, toda essa diversidade deveria encontrar uma disposição harmônica, cujo limite em breve fará saltar aos olhos contradições nem sempre tão aparentes. Chega a tomar Espirito das Leis para mencionar a capacidade de unificação da religião cristã que é identificada a partir da caridade, dos cultos públicos e dos sacramentos. Tal religiosidade se apresenta ao autor como o terreno ideal para os objetivos da ciência da economia política; embora não afirme de modo literal, permite supor que se trata de uma condição necessária. Silva Lisboa também enfatiza a fidelidade de Portugal à tal religião, o que entende ser mais um fator positivo para a adoção dos princípios da economia política e a construção do bem comum no império lusitano (cf. LISBOA, 1819, p. 07).

Ainda em Estudos do bem comum, quando passa a tratar a respeito da própria economia política, faz opção pelos autores ingleses, a fim de destacar a construção do bem comum que essa ciência poderia orientar. Sinaliza o desejo pela formação de um comércio universal, benevolente e pacificador de todas as 
comunidades, a partir de ideias gerais que atribui ao moralista Thomas Gisborne.

\begin{abstract}
... propagar a Lei Evangélica de Luz e Revelação às Gentes para a glória de Deus, e paz aos homens benévolos, visto que um dos veículos de execução destas Leis é o Comércio franco legítimo, que tende a animar, bem dirigir, e generalizar os trabalhos úteis da Cooperação Social, e dar o maior recíproco valor aos frutos da terra e indústria de todos os Países (LISBOA, 1819, p. 08).
\end{abstract}

Passa a citar literalmente o mesmo Thomas Gisborne, agora indicando a obra Inquirição dos deveres dos homes, para reafirmar a estreita relação entre o transcendente propósito do comércio, cujo destino fora dado pela Providência com a finalidade de promover um leque de benfeitorias, tais como o cultivo da terra, a extração de seus tesouros, aguçar a indústria do homem, unir a espécie bumana em laços de fraternal conexão, além do que entende ser muitas outras benesses, com lugar ao progresso da civilização, a extensão da ciência e a recepção do cristianismo. Aproximando-se do final de sua argumentação acerca da necessidade e importância dos estudos do bem comum, Silva Lisboa volta a enfatizar a estreita relação entre a riqueza das nações e a moral que lhe é proveniente da religiosidade cristã. Identificar e promover os princípios da economia política faria avançar ao último fim, a que todos os desígnios e dispensações de Deus, bem como raios de luz convergentes a um ponto central, parecem evidentemente dirigidos, ao aumento da soma da Geral Felicidade (cf. LISBOA, 1819, p. 08).

A economia política e a fé cristã se encontram e mesmo se complementam na cosmologia de Silva Lisboa através de um conceitual apreendido junto à filosofia natural. Sua visão geral de mundo não identifica contradições entre culturas tão diferentes. Considerando o que está sugerido desde o prefácio da obra e já explorado aqui, no funcionamento da sociedade que Silva Lisboa extraíra dos mestres ingleses nada seria vago e arbitrário, mas sim em conformidade com leis constituídas pela Inteligência Infinita que ligou o Físico ao Moral. A identificação e esforço para estar em conformidade a tal legislação cabe à ciência da economia política (cf. LISBOA, 1819, PREFÁCIO). Resta investigar o paradigma de sociedade que surgirá dessa relação por ele concebida entre o problema da riqueza das nações e o problema da moral.

Já no segundo capítulo da primeira parte de Estudos do bem comum, sob explícita orientação da economia política de Adam Smith, afirma que a sociedade 
civilizada deveria estar composta por três classes, a saber: proprietários, capitalistas e assalariados. No desenrolar do mesmo capítulo, analisa que o surgimento e a formação dessas classes teria complicado o que chama de Sistema Social. Mesmo sem aprofundar investigações acerca das classificações elaboradas pelo autor, cabe levantar algumas questões a partir da apropriação que fez Silva Lisboa de um conceitual retirado da filosofia natural. De antemão, nota-se o emprego do termo e mesmo do conceito de sistema; a partir dele pressupõe a existência de leis a serem identificadas para melhor explorar seu funcionamento. No entanto, as classes também são apresentadas como fruto de uma dada transformação, remetendo o leitor à ideia de processo histórico. Isso imprime alguma coerência interna ao conceito de civilização, também presente no trecho em análise (cf. LISBOA, 1819, p. 10).

A partir de tais concepções, o autor projeta um tempo histórico bastante dilatado, traz à tona especulações a respeito das mais antigas formas de organização social, para encaminhar, de modo um tanto resignado, a conclusão de que a dita transformação trouxe desigualdade de condições e fortunas, conflitos de interesse e direito, diante do que surgiu a necessidade um Estado regido por leis, a substituir organizações anteriores, por ele vistas como mais simples e ali exemplificadas a partir das antigas sociedades patriarcais e tribais de origem remota, tidas pelo mesmo autor de modo idílico, ainda que não tenha estendido comentários a esse respeito (cf. LISBOA, 1819, p 11, 12).

Ao ampliar o questionamento, é razoável concluir que segundo a coerência interna que Silva Lisboa pretendeu conferir à obra, o instrumental oferecido pelas teorias a que se filiava também encontrava limites para suas generalizações diante do processo histórico. As classes, a constituir a mencionada civilização, seriam todas fruto de um processo transformador ocorrido ao longo do tempo. Porém, se a análise permanecer limitada ao capítulo em questão, sob título Origem da ciência da economia política, o quase absoluto silêncio do autor acerca do caso brasileiro é suficiente para uma possível frustração inicial dos pesquisadores voltados à temática semelhante àquela aqui sugerida. Muito pouco surge a respeito da sociedade a que o próprio autor pertencia. O modelo analítico por ele adotado parece ser, à primeira vista, por demais generalizador para ser projetado sobre tantos particularismos. 
Afinal, um dos maiores problemas a ser resolvido por Silva Lisboa seria o de deslocar suas considerações teóricas, explorando possibilidades de execução do projeto de civilização idealizado a partir do surgimento das mencionadas classes, sobre uma situação local cuja maior característica era persistência e predominância do trabalho escravo. O autor apenas esbarra no tema, sem qualquer menção ao Brasil, para encerrar o capítulo exaltando os modernos, a quem coube o início de uma formulação mais precisa da economia política. Enquanto descreve o processo de surgimento da desigualdade, e de alguma forma contextualiza a origem remota da economia política, passa pelo tema do escravismo.

\begin{abstract}
... o intitulado Direito das Gentes, que autorizou o reduzir à escravidão os prisioneiros de guerra, sem distinção de ser esta justa, ou injusta. Os vencedores se intitularam senhores, e os vencidos ficaram cativos perpetuamente, transmitida a sua condição aos filhos.

Os antigos Estados fizeram a distinção civil entre livres, escravos e libertos [...] Por esse simples expediente se formou a geral subordinação e se assegurou a subsistência, defesa e riqueza das Nações. Porém ao mesmo tempo se organizou a extrema desigualdade das condições, e a inexterminável indigência e miséria dos povos; sendo os respectivos governos mais ou menos regulares, ou despóticos, conforme os graus de civilização, que a Religião, o Comércio, e os estudos das Letras, foram lenta e gradualmente introduzindo. (LISBOA, 1819, p. 12).
\end{abstract}

Embora reconhecendo que a partir dela se fez a riqueza de antigas nações, imediatamente após o momento em que surge a crítica à desigualdade, que segundo o desenrolar da própria obra estará mais bem exemplificada pela condição de escravo, Silva Lisboa volta a relacionar a ciência da economia política à moral religiosa. Ambas atuaram na caracterização dos antigos governos e suas respectivas participações estiveram diretamente relacionadas ao chamado processo de civilização. $O$ autor não passa sequer pelo termo Brasil, muito menos faz qualquer emprego direto dos conceitos de sua teoria geral sobre os particularismos do regime escravista de sua terra natal, todavia, está registrado ali que a ciência e a moral religiosa, tomadas por ele como linhas mestras de sua cosmologia, também possuiriam a finalidade de instrumentalizar a superação do escravismo, na medida em que o comércio e religião atuariam como agentes em um processo histórico rumo à civilização, segundo o qual essa forma de trabalho e divisão social deveriam ser superados. 
Sim, Silva Lisboa pode ser tratado como um conservador, mas seu conservadorismo não é uma mera obviedade. Em artigo publicado pela Revista de História, Pedro Meira Monteiro ${ }^{3}$ traz questões acerca do caráter conservador que de modo recorrente foi atribuído a Silva Lisboa pela historiografia. Intitulado $O$ 'reacionário', o texto já encaminha o problema a partir de seu subtítulo em forma de questão, Muitos historiadores falam mal do Visconde de Cairu. Será que ele merece isso? Deste modo, Meira Monteiro reconhece o fato de que Silva Lisboa tem sido mais detratado do que reconhecido ao longo da história, mas prefere chamar a atenção ao seu caráter polêmico e contraditório, observação que pretende estar justificada ao reconhecer em Silva Lisboa um convicto defensor do liberalismo econômico e ao mesmo tempo sua imensa preocupação com o controle social (MONTEIRO, 2008).

Embora a presente análise tenha optado por não utilizar o termo contraditório sem devidas ressalvas, tende a concordar de modo geral com a necessidade de se compreender o caráter polêmico da obra de Silva Lisboa, de modo a esquivar-se de respostas imediatas, quase sempre fruto de questões muito simplificadoras. Silva Lisboa possuía em seu horizonte a necessidade de abandonar o problema do escravismo e fez defesa dessa tese. A análise a respeito de tal condição econômica, social e mesmo moral, assim como a própria necessidade de sua superação, estavam submetidos a uma visão geral de mundo, uma cosmologia, a qual comportava elementos culturais dispostos segundo uma coerência interna que ele acreditava estar conferindo à sua obra.

Através dessa cosmologia, na qual a filosofia natural muitas vezes operava como uma espécie de matriz conceitual, ele entendia estar elaborando uma literatura dotada de alguma lógica interna. Muitas vezes foi e poderia continuar a ser tratado como conservador, se comparada sua proposta de superação do escravismo a outras também debatidas em seu tempo e contexto histórico, entretanto tal classificação não parece ser muito esclarecedora. Faz-se necessário compreender a própria lógica de seu discurso, fazer saltar aos olhos seus limites internos, cuja identificação e análise é imprescindível, sobretudo a todos aqueles que possivelmente estejam interessados em julgar a obra e até

${ }^{3}$ O 'reacionário'. Muitos historiadores falam mal do Visconde de Cairu. Será que ele merece isso? Artigo publicado em agosto de 2008 pela Revista de História da Biblioteca Nacional. Consultado em 8 de julho de 2014. IN: http://www.revistadehistoria.com.br/secao/retrato/o-reacionario. 
mesmo o autor, que se esforça para elaborar a apresentação e mesmo a defesa das propostas de uma economia política de cunho liberal sobre uma sociedade cuja condição escravista está sendo por ele criticada, sem com isso deixar de lado aspectos que, se comparados a outras propostas de superação, não deixam de ser conservadores.

Atendo-se a essa proposta, é possível notar ao longo do texto que a ciência da economia política passa a ceder espaço à argumentação de envergadura moral. Na medida em que o interesse é projetado ao emprego de conceitos da filosofia natural na relação que o autor pretendeu estabelecer entre esses dois campos do saber, economia política e moral religiosa, também se torna possível conduzir a análise à problemática da sociedade e as transformações sociais necessárias, conforme o entendimento de Silva Lisboa. Tal procedimento traz à tona os limites quando os conceitos de ordem geral deparam-se com obstáculos encontrados junto aos particularismos de uma sociedade caracterizada pelo modelo escravista.

\section{Os limites da síntese na projeção de uma sociedade}

Nos momentos em que diante dos problemas apresentados pelo caso brasileiro, a formação histórica que era de maior e especial interesse do autor, parecia restar do instrumental teórico da economia política apenas a terminologia, Silva Lisboa então se desdobra a fim de aproximá-lo de modo mais estreito aos problemas da moral. Para essa tarefa, faz uso de conceitos tidos como universais, sendo possível notar sua necessidade em compartilhar uma ideia central à filosofia do Iluminismo. Salta aos olhos a clareza com que Silva Lisboa explicita a ideia de universalidade do gênero humano; mais do que apenas fazer uso de uma premissa teórica embutida em suas análises, o autor preocupa-se em apresentá-la ao leitor. Trata-se de uma postura típica de parte considerável dos intelectuais de seu tempo, tributários de uma concepção estreitamente ligada ao ideário ilustrado, a ideia de natureza humana, hoje sujeita a críticas diversas, mas que ainda ocupava lugar central nas investidas filosóficas no início século XIX. 


\begin{abstract}
Sendo, a constituição humana homogênea em todos os países, a mesma Lei deve reger em todas as Nações, ou Estados, que se podem considerar outras tantas Casas particulares, ou ramificações de Famílias, oriundas dos mesmos pais. Circunstâncias do lugar e tempo podem necessitar algumas acidentais, mas não substanciais, modificações daquela Lei (LISBOA, 1819, p.138).
\end{abstract}

Nesse sentido, já na segunda parte de Estudos do bem comum, sob sugestivo título Princípios fundamentais da economia política, e cooperação social, o autor passa a estabelecer tais relações, a serem projetadas de modo universal.

Economia Política geral tem por objetivo inquirir o Verdadeiro
Sistema Social, fundado nas Leis Fundamentais da Ordem Moral,
isto é, o Plano Econômico do Criador, e que se diz Economia da
Providência a respeito da Espécie Humana, a fim de ter fundos
do necessário cômodo, e delicioso à vida, além dos que a
Natureza espontaneamente produz, e oferece nas terras e águas
que a cobrem; e, em consequência, para se poderem os homens
multiplicar, e bem conviver na sociedade, aperfeiçoando os
respectivos dotes de espírito, e corpo, quanto é compatível com a
sua atual constituição, evidentemente decaída de seu primordial
estado (LISBOA, 1819, p. 140).

Segundo sua cosmologia, a filosofia natural promove a possibilidade de estabelecer a relação, segundo ele necessária, entre a riqueza da nação, sob orientação da economia política, e a moral, sob orientação de sua religiosidade cristã, conforme a coerência que impôs ao texto desde os primeiros parágrafos. A ideia de leis fundamentais, uma das balizas mestras da filosofia natural dos modernos, deve operar nos estudos encaminhados pela economia política, cujo propósito envolve perguntar acerca do sistema social, a respeito do mecanismo que, em última instância, trata-se de um Plano Econômico do Criador. O conceitual aprendido junto à filosofia da natureza opera de modo a aproximar ciência e religiosidade. Tal postura permite apontar em sua formação intelectual a profunda influência das Reformas Pombalinas na Universidade de Coimbra, onde Silva Lisboa esteve entre 1774 e 1779, quando então retornou à colônia.

Dando continuidade à sua explanação, Silva Lisboa estabelece distinções entre o que chama de economia política geral e economia política particular, sendo aquela voltada ao progresso geral da civilização, e esta última à tarefa de promover a indústria e riqueza nacional. Neste ponto reside os limites impostos à sua teoria pela formação histórica e social de cada nação, ou seja, dos casos particulares. Silva Lisboa demonstra ter claro para si as dificuldades de submeter o caso particular aos conceitos de ordem geral, embora enfatize que 
seu interesse reside sobre o caso nacional, o caso do Brasil, naquele momento pensado por ele ainda como extensão do império português.

\begin{abstract}
Ainda que vários Princípios de Economia Política Geral sejam certos, e luminosos, todavia eles consideravelmente se modificam e restringem-na sua aplicação às operações do Governo de cada Nação, pela necessidade de se atender as ditas considerações. $\mathrm{Na}$ verdade, quando ainda os melhores e mais incontestáveis princípios especulativos de Economia Política se aplicam aos usos práticos da vida civil, eles passam (por assim dizer) pela densidade dos intrincados costumes, hábitos, estatutos, erros, estabelecimentos, e prejuízos inveterados dos povos... Por isso não é sempre possível, ou seguro, aplicar (cega e indiscriminada, e absolutamente) tais princípios, tanto na direção da indústria de cada país, como no seu regime econômico; e, em consequência, pode ser este mais ou menos liberal (sem nota contra a sabedoria da Administração) conforme aos lugares, circunstâncias, e relações com os diversos Povos e Governos (LISBOA, 1819, p. 142).
\end{abstract}

Embora esteja a tratar dos princípios fundamentais, com muita clareza Silva Lisboa adverte seu leitor acerca da necessidade de se levar em conta as condições específicas de cada nação, no momento em que cada uma delas fossem submetidas a tais princípios gerais. Cita um leque diversificado de eventuais particularismos, a exemplo de bábitos, densidade dos costumes, estatutos, estabelecimentos. Contudo, ainda que mais uma vez não mencione diretamente o Brasil, estende suas exemplificações trazendo à tona o que para ele era em sua nação o mais pertinente dos particularismos, e ele é de cunho sobretudo econômico e social.

É óbvio, que uma Nação de povos incultos não pode ter igual economia política, que uma de gente civilizada, e adiantada em artes e ciências. Não pode também ser exatamente a mesma economia política, em uma Nação onde se acha estabelecida a Lei do cativeiro, ou da servidão da gleba, e em outra onde os povos gozam de plena liberdade civil, e fazem bom uso dela (LISBOA, 1819 , p. 142).

De início, cabe destacar que no trecho acima o autor utiliza a expressão economia política, escrevendo as inicias em letras minúsculas. É possível entender que sua intenção era distinguir tal utilização no contexto particular, acima citado, daquelas onde buscou mencionar a ciência de mesmo nome, dotada de seus reconhecidos princípios de ordem geral. Além dessa rápida observação, deve ser registrado aqui a comparação que é sugerida pelo autor. Novamente, é possível concluir que Silva Lisboa tinha o escravismo como a condição social, econômica e moral mais oposta à condição de civilização. No que diz respeito 
ao processo histórico, a existência de um sistema escravista era o fator que mais comprometia o projeto civilizatório, a ser buscado a partir dos princípios da economia política e para a realização da cooperação social, cuja finalidade maior seria alcançar o bem comum.

A partir dessa lógica, à sociedade escravista que é então analisada cabe a necessária superação, porém, sem drásticas rupturas, sobretudo aquelas de caráter revolucionário. Sendo assim, caberá encaminhar um processo histórico que jamais deixe de considerar as leis que a divindade estabeleceu para o progresso das nações e de toda a humanidade. A identificação e a observância dessas leis estão entre as funções da economia política. O Estado capaz de encaminhar esse processo histórico, realizar esse projeto de nação, levará seus habitantes ao bem comum. Ao refletir sobre fatores que impedem o desenvolvimento do que denomina por indústria, o autor chama a atenção para a ignorância e a opressão, capazes de diminuir o trabalho, a produção e progressivamente agravar a miséria da população. Assim, o texto de Estudos do bem comum ganha sequência de modo a deparar-se novamente com o problema de uma economia e de uma sociedade fundamentada no escravismo.

Já na terceira parte de Estudos do bem comum, no décimo quarto capítulo, intitulado Observações do Professor Malthus sobre a indústria, Silva Lisboa destaca a importância de toda nação em trazer para si o maior número de pessoas industriosas, menos ignorantes, conforme seu entendimento. Nesta ocasião, remete o leitor a uma nota de rodapé em tom mais panfletário que reflexivo, como se estivesse a assumir uma postura mais política e mesmo parlamentar. Em tal passagem, aproxima ao caso brasileiro a proposta que está a apresentar e defender.

\footnotetext{
Esta regra deve ser bem notada neste Reino, onde ainda tanta gente receia a importação de industriosos da Europa, que sabem fazer obras de indústria, que são desconhecidas, ou mui rudes no país, e que, pelo hábito de trabalho regular, atividade do espírito em perseverar nas empresas econômicas, e superior inteligência, são capazes de achar e multiplicar as produções úteis. Mais valem mil industriosos das Nações civis, que dez mil africanos; e todavia tão obstinadamente ainda se insiste na importação de bárbaros, de entendimento broncos, e braços repugnantes aos trabalhos necessários! (LISBOA, 1819, p. 329).
}

A partir de leituras que fez da obra de Thomas Malthus, autor por ele também tomado como autoridade em economia política, Silva Lisboa tece sua 
crítica à parca iniciativa de seu reino em trazer mão de obra ligada às atividades daquilo que chama de indústria. A aplicação de tal princípio se faz ainda mais necessária diante do particularismo brasileiro, ligado ao largo emprego da mão de obra escrava, cuja importação volta a criticar mais adiante. A ciência encaminha o rumo mais promissor, segundo o qual o fim do escravismo é uma necessidade, no entanto, impressiona o modo com que faz menção às pessoas provenientes da África, empregadas como mão de obra escrava no Brasil. Os então responsáveis por uma parcela incomensurável do trabalho realizado no Brasil, recebem por parte do autor adjetivações como bárbaros, broncos e repugnantes.

Aos olhos de leitores contemporâneos minimamente sensatos, repugnante é tal face do pensamento de Silva Lisboa a respeito de alguns aspectos da mão de obra escrava, quando não dos próprios escravos. Todavia, ao continuar a leitura do próprio Estudos do bem comum, no sexto capítulo da mesma terceira parte, voltado a estender análises sobre as causas do que classifica ser a indústria ativa e regular, em meio ao conjunto de causalidades abordadas o leitor se depara com nova e explícita defesa pelo fim da escravidão. Para Silva Lisboa, o escravismo não era um mal necessário, como por longo tempo ainda insistiriam muitos intelectuais e políticos brasileiros do século XIX. Refuta a ideia de que sem escravos não há colônia; tem por cegos aqueles que não reconhecem que a civilização demanda o fim do escravismo, e menciona de modo crítico o fato de que os mais fiéis chegam a atribuir tal progresso e melhora ao influxo da religião cristã (LISBOA, 1820, p. 25).

Já no décimo sétimo capítulo da terceira parte, cuja publicação se deu em 1820, tratado como Seção II de Estudos do bem comum, encontram-se rápidos comentários sobre os estudos de Thomas Malthus a respeito da questão populacional. Ali, Silva Lisboa reitera sua concepção de que o escravismo deve ser combatido, porque representa o polo oposto ao progresso. Desta vez, faz críticas à teoria de Malthus, e sugere ser o descompasso entre o crescimento populacional e o aumento da produção uma falha dos Estados, ou seja, das legislações criadas pelo homem. Embora reconheça a importância da obra de Malthus e sua grande circulação entre os interessados em economia política, afasta-se de suas concepções, porque identifica melhores respostas na esfera da 
moral, conforme a coerência interna de seu texto, onde os Estados foram tomados como entes morais.

... [Malthus] atribuindo às Leis da Natureza grande parte das misérias, que aliás evidentemente são as consequências necessárias de várias Leis desumanas, que tem organizado a propriedade de poucos, e a desgraça de inumeráveis, os quais são desanimados de ativa e regular indústria, pela quase física impossibilidade de melhora de condição; como são as Leis da escravatura, e das restrições da honesta circulação do trabalho, e do comércio legítimo, que muito tiram o interesse, e estreitam a esfera do trabalho produtivo (LISBOA, 1820, p. 63).

Tomado para análise o trecho citado acima, nota-se que a fim de justificar a crítica elaborada a uma das principais propostas de Malthus, Silva Lisboa refuta uma causalidade de ordem natural em favor de outra, de ordem cultural. Onde o autor inglês atribui razões naturais, Silva Lisboa entende ser um equívoco na orientação que as sociedades humanas impuseram às suas respectivas legislações. Ainda que de modo sutil, a citação acima corrobora com as observações realizadas até então, pois, mediante a cosmologia de Silva Lisboa, a ciência da economia política deveria ser encaminhada sem contradições com o que entendia ser aspectos ligados a ordem moral. Ficará ainda mais evidente tal preocupação nos capítulos seguintes do mesmo livro, quando se permite mais uma vez observar a influência que os conceitos aprendidos junto à filosofia natural exerciam sobre a cosmologia do autor, de modo a promover o que ele entendia ser uma lógica interna à sua obra e sobre a qual buscou-se aqui lançar questionamentos, identificando seus limites explicativos.

No vigésimo e vigésimo primeiro capítulo, novamente os interesses são projetados ao exame das ideias de Malthus, agora acompanhadas daquelas formuladas por Humboldt, desta vez a respeito da influência da fertilidade das terras e do clima sobre a questão da indústria. A leitura e análise do que ali foi apresentado é muito sugestivo para a presente investigação. Embora o objeto abordado nesses capítulos seja o solo e o clima, Silva Lisboa projetou questões ligadas à filosofia natural àquela temática, esperando com isso alcançar o arranjo conceitual que deveria aproximar ciência e moral, além de terminar a discussão com o particularismo que fora tomado aqui como o mais pertinente para conhecer e analisar o caso da sociedade brasileira, o problema da escravidão. 
Silva Lisboa identifica na análise oferecida por Malthus a ideia de que terras férteis e bom clima não favoreciam, de modo necessário, a indústria, riqueza e população; as facilidades proporcionadas pela presença de tais fatores levariam as respectivas populações a valorizar o que classifica de luxo do descanso em lugar do luxo do gozo, sendo que este último exige esforços mais sadios para corpo e mente. Lembra que Malthus apontava o aumento da população, a acumulação de capital, as invenções de poupar trabalho e a fertilidade das terras como fatores para o progresso da riqueza. No entanto, Silva Lisboa limitou-se apenas ao último deles, alegando ser o mais ligado à teoria geral da indústria, além de ter aplicação prática ao Brasil, dotado de terras férteis. Em última instância, embora reconheça a autoridade do pensador britânico, refutará a ideia de que as condições naturais favoráveis criariam hábitos de indolência na respectiva população (cf. LISBOA, 1820, p. 75 - 76).

Após mencionar os exemplos que Malthus foi buscar na obra de Humboldt, onde aquele havia encontrado larga descrição sobre as péssimas condições de vida ou mesmo a miséria em que grande parte da população se encontrava nas colônias espanholas, tal como o México, Silva Lisboa passa a discutir, apontar limites e mesmo tecer críticas ao que anteriormente apenas apresentara. Inicia o texto destacando a filiação das análises econômicas de Malthus às regras de Newton, com o que afirma também estar em concordância. Sendo assim, apresenta ao leitor uma delas, A natureza nada faz. debalde = ela é concorde consigo mesma.

Em observância destas regras, não se deve atribuir à fertilidade das terras a inércia dos seus naturais, quando outras causas dão solução ao fenômeno; e é evidentemente contraditório dar a Natureza fertilidades às terras, e ao mesmo tempo dar torpor aos espíritos e corpos para não se aproveitar a sua dádiva (LISBOA, 1820, p. 76).

Feito o apelo literal, ainda que facilmente criticado, a um princípio geral da filosofia natural newtoniana, segue Silva Lisboa a discutir e refutar a proposta de Malthus, a atribuindo

... um paradoxo, que repugna a razão desprevenida; a irresistível evidência da Ordem Cosmológica; a justa Teoria das Causas Finais; e enfim ao senso comum de todos os indivíduos e Estados, que preferiram sempre os férteis, saudáveis, e geniais países, para cultura, compra, ou conquista, com os maiores sacrifícios de trabalho, tesouro e sangue. Nenhum conquistador preferiu a Arábia à Índia... (LISBOA, 1820, p. 78). 
A se somar à argumentação acima, que passa pela ideia de razão, ordem cosmológica, causas finais e sobretudo ao senso comum, empregado enquanto o saber construído pela recorrência das relações estabelecidas entre os fatos, na esteira da filosofia de tradição anglófila, onde Silva Lisboa encontrara nomes como o de Smith, Malthus, David Hume, além do referencial epistemológico maior de Isaac Newton, todos por ele citados de modo literal ao longo da obra, o autor segue seus comentários sempre dirigidos às possibilidades de melhor aproveitamento de tudo o que a natureza possa oferecer, ou a superação diante das dificuldades de solo e clima com que outras nações venham a se deparar. Segundo seu entendimento, os esforços humanos, a partir de capacitações de sua própria natureza ${ }^{4}$, conferidas pela Providência, sempre serão suficientes para promover a indústria e o bem comum, conforme orientações da economia política.

Deste modo, conforme conclui a análise aqui proposta, em meio ao discurso de Silva Lisboa, a ciência da economia política deveria estar atenta aos desígnios de uma ordem moral, proveniente de sua religiosidade cristã, como é possível demonstrar a partir das citações abaixo, nas quais de modo muito claro e direto o próprio autor o faz já nas primeiras considerações apresentadas em sua obra Princípios de Economia Politica.

O mundo físico rege-se por leis simples e fecundas, que lhe dão ordem, harmonia, beleza e perpetuidade. Algumas daquelas leis são conhecidas pelos homens e segundo as mesmas leis regulam suas ações, previnem danos e adquirem muitos bens da vida. Reunidos em sociedade constituem um mundo moral, que parece também dever ser regido por leis de igual simplicidade e fecundidade, para viverem em paz e abastança. O conhecimento e o exercício destas leis é o que se chama ciência e prática de Economia que, segundo sua etimologia, significa a lei da casa.

A sábia Economia do Criador se manifesta claramente na infinita variedade com que diversificou as terras, climas e habilidades, dando a cada país e indivíduo suas produções, vantagens e aptidões particulares; evitando-se assim uma uniformidade desagradável e estabelecendo-se não menos uma dependência e aliança recíproca dos homens e Estados, para mutuamente se ajudarem e desfrutarem os dons da Providência (LISBOA, 1956, p. 112).

\footnotetext{
${ }^{4}$ Coerente com a já mencionada ideia de natureza humana, Silva Lisboa admite que a natureza poderia influir no corpo físico e mesmo político, mas jamais alterar a constituição humana, de modo a amortizar o inato princípio do que denominava amor do gozo e da melhor condição de vida, tidos por ele como motores da indústria, causas necessárias para o progresso da civilização (cf. LISBOA, 1820, p. 77).
} 
A filosofia natural que é compartilhada pela cosmologia de Silva Lisboa perpassa muitos dos títulos que compõem sua obra e modo recorrente estabelece as devidas relações entre a economia política e a moral religiosa, cuja orientação deveria estar refletida ao máximo nas próprias leis formuladas para organizar o Estado. Os conceitos encontrados junto à filosofia natural e tais relações eram determinantes para nortear suas leituras e análises projetadas sobre o caso da sociedade brasileira. Esta relação, concebida por uma cosmologia muito influenciada pela filosofia da natureza, permitiria garantir a razoável aplicação dos conceitos gerais de sua ciência ao caso particular do Brasil, a partir do que passava a estender suas críticas até o problema do escravismo, o qual surge cada vez mais como limitador da aplicação dos conceitos encontrados na cultura ilustrada, em especial na economia política.

Já no capítulo seguinte, mantém os comentários e críticas voltados às ideias malthusianas, em específico ao problema da fertilidade das terras como fator condicionante de um dado descanso, indolente e nada positivo, segundo a proposta de Malthus. Porém, à medida em que a apresentação e os comentários sugeridos por Silva Lisboa vão tomando corpo, a atenção do leitor mais uma vez é conduzida ao que está sendo destacado na presente ocasião, a questão da sociedade escravista.

\footnotetext{
Mostra-se pois a todas as luzes, que a fertilidade das terras é a Mercê da Providência, que constitui o maior Patrimônio das Nações, que são com ela mais favorecidas; e, sem ela, todas as mais causas que influem no progresso da indústria e riqueza são, comparativamente, impotentes. Ao Céu pois, com mui especial razão devem com gratidão levantar as palmas os habitantes de tais terras, e podem com verdade, e religiosos êxtases, dizer - Deus nos doou este descanso. Este descanso porém, havendo facilidade de instrução, dá energia ao espírito para meditar nas Leis e Obras do Criador.

[...] Mas devo sempre dizer, que não poderemos regozijarmos de aclamar os campos bem-aventurados, senão quando a Divina Providência permitir, que a Agricultura se faça por braços livres (LISBOA, 1820, p. 86).
}

O descanso proporcionado pela fertilidade das terras brasileiras não iria, de modo necessário, conferir ao espírito de sua respectiva população a indolência que muitos estudiosos ainda viriam atribuir, embora já mergulhados nos séculos seguintes. Uma vez condicionado à instrução, ao contato e produção dos saberes, condição necessária e suficiente para que tal descanso ganhasse sua devida positividade, passaria então a servir não somente para a 
ampliação da riqueza nacional, como já apontado, mas também e sobretudo, segundo Silva Lisboa, às reflexões de cunho religioso. Entretanto, mais uma vez os brasileiros não estariam autorizados ao regozijo de tais benesses enquanto a nação convivesse com o emprego do trabalho escravo.

Os universais oferecidos pela ciência da economia política, que estariam a ruir diante da condição particular de uma sociedade escravista, segundo o autor teriam encontrado salvaguarda a partir da apropriação que Silva Lisboa fizera da filosofia natural dos modernos e seus conceitos de ordem universal, cuja importância é central na composição de sua cosmologia, e que por sua vez possibilitava submeter o caso particular do Brasil a uma dada concepção de processo histórico a ser percorrido também pelo progresso da riqueza brasileira. Cristianismo e ciência da economia política falam a partir de universais, a filosofia natural promove tal aproximação porque ela era tida então como a mais bem acabada literatura dos conceitos de caráter universal. A despeito dos limites que o instrumental da economia política poderia encontrar frente aos particularismos de casos em específico, e que muitas vezes levou o autor a recorrente silêncio acerca da própria sociedade em que vivia, uma leitura e análise mais minuciosa e pormenorizada foi capaz de destacar um instrumental teórico que capacitasse o autor a estender seus pareceres até mesmo sobre o caso da sociedade escravista então vivenciada pelo Brasil, e ainda segundo ele submetida à necessidade de transformações ao longo do processo histórico.

O poder generalizante do conceitual por ele utilizado deveria permanecer garantido, a despeito de situações particulares de sua nação. Se por um lado sentia-se mais confortável para discorrer sobre a humanidade, a natureza humana, o progresso e a civilização, por outro, ainda se via capaz de superar impasses com os quais se deparava quando a análise fosse dirigida a uma sociedade escravista. Dotado de uma visão geral de mundo em larga medida regida pela filosofia natural dos modernos, Silva Lisboa buscava aproximar ciência e moral religiosa, para assim se colocar ao estudo de caso que a ele mais interessava. Como identificado no início deste texto, através da relação entre a ciência da economia política e a moral religiosa, buscada através de um conceitual encontrado na filosofia natural, em Estudos do bem comum Silva Lisboa não só submeteu o problema do escravismo às suas críticas e sugeriu 
sua superação, como também demonstrou um olhar de certo modo positivo sobre o desenrolar da história do caso brasileiro e de sua respectiva sociedade.

Ainda acerca da característica escravista da sociedade brasileira, caberia registrar o olhar positivo que Silva Lisboa projetava para um futuro no qual a mão de obra livre estivesse na ordem do dia. A despeito de colocações que hoje devem ser vistas de modo lamentável e condenável a respeito da terminologia e mesmo de alguns dos conceitos com que abordava a temática, tinha claro para si que a escravidão era uma chaga a ser eliminada. A princípio cabe observar tal terminologia, com a qual esta pesquisa já se deparou, mas pode ser retomada neste momento a partir de outro trecho, mais uma vez encontrado em nota de rodapé, e novamente em tom mais parlamentar do que acadêmico. Ele se encontra no momento em que o autor refuta todas as justificativas utilizadas para defender o largo emprego da mão de obra escrava, indígena e africana, em colônias hispânicas, apontando suas consequências, sempre negativas.

Estes efeitos, a olhos vistos se manifestam em hórridos exemplos de crimes e atentados da população factícia africana. Foi fatal erro político constituir uma nação, na maior parte composta de gente que não nasce no país, e que não pode ser a ela afeiçoada, nem presa pelas cordas do coração. Estou certo, que, enquanto ela durar, o Brasil não pode ter a boa indústria de que é capaz. Portanto, desde já protesto, uma vez por todas, que a teoria da indústria, enquanto se aplica a este Reino do Brasil, pressupõe o seu progressivo desenvolvimento, desde a época em que, A Sabedoria do Governo, cessar o sistema de cativeiro (LISBOA, 1820 , p. 44).

Se anteriormente fora destacado aqui adjetivações como bárbaros, broncos e repugnantes, acima tem-se a expressão população factícia, destacada pelo próprio autor em itálico, somada à pretensa conclusão sobre a impossibilidade daquelas referidas pessoas em desenvolver afeto à nação. Ao longo de seus escritos, farto é o número de passagens com menções marcadas por esse espírito mais do que depreciativo, incapaz de projetar um olhar de caráter humanista ou humanitário. Embora tenha realizado o necessário registro, não é de interesse desta pesquisa aprofundar análise sobre tais pareceres, bem como tecer julgamentos sem a devida profundidade analítica que a temática merece e certamente receberá.

No momento, cabe ressaltar que o autor tem o fim da escravidão como condição necessária para o pleno emprego das orientações que a economia 
política teria a apresentar para o desenvolvimento e ampliação da riqueza nacional. Seu otimismo acerca da prosperidade do Brasil deveria passar por esse requisito de primeira ordem. É razoável concluir que projetou olhares mais positivos sobre sua nação, uma vez que a mesma já tivesse superado o escravismo. A relação entre a ciência da economia política e a moral de cunho religioso, forjada através de um farto e reconhecido leque de conceitos e termos oferecidos pela filosofia natural dos modernos, não somente permitiu Silva Lisboa refletir e discorrer a respeito de sua sociedade em particular, como também projetar um olhar positivo e otimista a respeito do desenvolvimento histórico de sua nação.

A filosofia da natureza por ele compartilhada fornecia à sua cosmologia elementos a partir dos quais relacionava ciência e moral religiosa. A partir dessa visão de mundo, buscava compreender aquela sociedade e interferir em seu respectivo processo histórico, cujo particularismo da escravidão, segundo o seu entendimento, não deveria continuar a comprometer a funcionalidade dos conceitos de ordem geral, a partir dos quais projetava suas análises. Justamente aí deparava-se com os paradoxos bastante difíceis de serem superados, quando então tangenciava o problema do escravismo ao longo de sua argumentação, permitindo notar que a aplicação dos conceitos sobre os quais se apoiava somente alcançaria plena viabilidade mediante o fim do modelo escravista. No entanto, o poder de generalização atribuído aos mesmos conceitos, somado à ideia de processo histórico, permitia a Silva Lisboa projetar aquele instrumental teórico e analítico também ao caso brasileiro, e tal generalização era pretensamente alcançada a partir de concepções encontradas junto à filosofia natural dos modernos, elementos centrais de sua cosmologia, por conseguinte determinantes na construção de sua obra.

\section{Referências}

ABBAgnANO, N. Dicionário de Filosofia. São Paulo: Martins Fontes, 2000.

ALMODOVAR, Antonio. Processos de difusão e institucionalização econômica política no Brasil. IN: CARDOSO, José Luis (org.). A economia política e os dilemas do Império-brasileiro (1790 - 1822). Lisboa: Comissão para comemorações dos Descobrimentos Portugueses, 2001. 
BOBBIO, N.; MATEUCCI, N.; PASQUINO, G. Dicionário de Política. Brasília: Editora da Universidade de Brasília; São Paulo: Imprensa Oficial do Estado, 2000.

BOTO, Carlota. Iluminismo e Educação em Portugal: o legado do século XVIII ao XIX. Petrópolis: Vozes, 2004.

BUTTERFIELD, Hebert. As origens da Ciência Moderna. Lisboa: EDIÇÕES 70. $1^{\text {a }}$ edição em inglês: The Origins of Modern Science, de 1949.

CABRAL, Alfredo do Valle. Vida e Escriptos de José da Silva Lisboa (1881). IN: Cairu, org. E. Vilhena de Morais. Rio de Janeiro, 1958.

CALAFATE, Pedro. A idéia de natureza no século XVII em Portugal. Lisboa: Imprensa Nacional-Casa da Moeda, 1994.

CARNEIRO, A. e Simões, A. (2000). Enlighthtenment science in Portugal: the estrangeirados and their communicating networks. IN: Social Studies of Science, 2000; 30/4, 591-619.

CARVALHO, Darcy. Desenvolvimento e livre-comércio: as ideias econômicas e sociais de Visconde de Cairu. São Paulo: Instituto de Pesquisas Econômicas, 1985.

CARVALHO, Rômulo. A história natural em Portugal no século XVIII. Lisboa, I.C.L.P., 1987.

CASINI, Paolo. Newton e a consciência européia. São Paulo: Editora da Universidade Estadual Paulista, 1995.

CASSIRER, E. A filosofia do iluminismo. Campinas: Unicamp, 1994.

CIDADE, Hernani. Lições e Cultura e Literatura Portuguesas. 2 volumes. Coimbra: Editora Limitada, 1975.

COGGIOLA, O (Org.). A Revolução Francesa e seu Impacto na América Latina. São Paulo: Nova Stella: Editora da Universidade de São Paulo; Brasília, DF: CNPq, 1990.

COHEN, I. B. e WESTFALL, R. S. (organizadores). Newton: textos, antecedentes, comentários. Rio de Janeiro: Contraponto; EDUERJ, 2002.

DECOLA, P. Diversité des natures, diversités des cultures. Montrouge: Bayard, 2010.

DIAS, José Sebastião da Silva. Portugal e a cultura européia (séculos XVI e XVIII). In: Biblos, Vol. XXVIII, 1953.

DOMINGUES, Francisco Contente. Ilustração e Catolicismo. Teodoro de Almeida. Lisboa, Colibri: 1994.

FORCE, James E.; POPKIN, Richard H. Essays on the context, nature, and influence of Isaac Newton's theology. Dordrecht/Boston/London: Kluwer Academic Publishers, 1990. 
FRANCO, A. A. de M., O visconde de Cairu. IN: Digesto Econômico. Agosto de 1947.

FRANCO, M. S. de C. As idéias estão no lugar. IN: Caderno de Debates, $\mathrm{n}^{\circ}$ 1, p. 61 - 64. São Paulo: Brasiliense, 1976.

GAUER, Ruth Maria C. A construção do Estado-nação no Brasil. A contribuição dos egressos de Coimbra. Curitiba: Juruá, 2001.

HAZARD, Paul. A crise da consciência européia. Lisboa: Cosmos, 1948.

HOLANDA, Sérgio Buarque de (direção). História Geral da Civilização Brasileira. São Paulo: DIFEL, 1985.

Raízes de Brasil. São Paulo: Companhia das Letras, 1995.

KIRSCHNER, Tereza Cristina. José da Silva Lisboa, Visconde de Cairu. Itinerário de um ilustrado luso-brasileiro. São Paulo: Alameda; Belo Horizonte: PUC-Minas, 2009.

LENOBLE, Robert. História da Idéia de Natureza. Rio de Janeiro: Edições70, 1990.

LIMA, Alceu do Amoroso. Época, Vida e Obra de Cairu. IN: José da Silva Lisboa - Princípios de Economia Política. $2^{\text {a }}$ ed. Rio de Janeiro, 1956.

LISBOA, E. (coord.). Dicionário cronológico de autores portugueses. Instituto Português do Livro Europa-América, 1985.

LISBOA, José da Silva. Princípios de Economia Política para servir de introdução à teoria Econômica do autor dos Princípios de Direito Mercantil. Lisboa: Impressão Régia, 1804.

Estudos do bem comum e economia política ou ciência das leias naturais e civis de animar e dirigir a geral indústria e promover a riqueza nacional e prosperidade do Estado. Rio de Janeiro: Impressão Régia, 1819-1820.

Constituição Moral de deveres do cidadão com exposição da moral pública conforme o espírito da constituição do império. Rio de Janeiro: Typographia Nacional, 1824-1825.

MELCHIOR, Elísio de Oliveira. Visconde de Cairu, sua vida e sua obra. Rio de Janeiro, 1959.

MONTEIRO, Pedro Meira. Um moralista nos trópicos: o visconde de Cairu e o Duque de la Rochefoucauld. São Paulo: Fapesp / Boitempo Editorial, 2004.

O 'reacionário'. Muitos historiadores falam mal do Visconde de Cairu. Será que ele merece isso? Artigo publicado em agosto de 2008 pela Revista de História da Biblioteca Nacional. Consultado em 8 de julho de 2014. IN: http://www.revistadehistoria.com.br/secao/retrato/oreacionario. 
NEWTON, Isaac. Princípios matemáticos de filosofia natural. São Paulo: Edusp, 2002.

Óptica. São Paulo: EDUSP, 1996.

NOVAIS, Fernando A. Portugal e Brasil na Crise do Antigo Sistema Colonial (1777-1808). $3^{2}$ edição. São Paulo: Hucitec, 1985.

NOVAIS, F. A.; ARRUDA, J. J. de Andrade. Prometeus e Atlantes na forja da nação. Introdução. IN: LISBOA, José da Silva. Observações sobre a franqueza da indústria, e estabelecimento de fábricas no Brasil. Brasília: Senado Federal, 1999.

OLIVEIRA, Daniel de Lara. Ciência moderna e newtonianismo no projeto pedagógico de Luís António Verney. São Paulo: Todas as Musas, 2013.

PAIM, Antonio. Cairu e o Liberalismo Econômico. Rio de Janeiro: Tempo Brasileiro, 1968.

PAULA, L. Nogueira de. Introdução. IN: Lisboa, José da Silva. Princípios de Economia Política. Rio de Janeiro, 1956.

ROCHA, Antonio Penalves. A economia política na sociedade escravista. São Paulo: Depto. de História - FFLCH - USP / Hucitec, 1996.

Paulo: Editora 34, 2001.

(Org. e Introd.). Visconde de Cairu (1756 - 1835). São

. ROCHA, Antonio Penalves. A escravidão na economia política. IN: Revista História, São Paulo, 120, p. 97-108, Jan/Jul 1989.

RODRIGUES, M. A. A Universidade de Coimbra e a elite intelectual brasileira na última fase do período colonial período colonial. IN: Revista de História das Idéias, v. 12, 1990.

SILVA, Beatriz Nizza. A Cultura Brasileira: da reforma da Universidade à independência do Brasil. Lisboa: Editorial Estampa, 1999.

Linguagem, cultura e sociedade. O Rio de Janeiro 1808 a 1821. Tese de Livre Docência. 1993. FFLCH - USP.

SKINNER, Q. Meaning and Understanding in the History of Ideas. IN: History and Theory 8, 1969.

Motivos, intenciones e interpretación. IN: SKINNER, Q.

Lenguaje, Política e História. Bernal: Univ. Nacional de Quilmes, 2007.

Interpretación y comprensión en los atos de habla. IN:

SKINNER, Q. Lenguaje, política e história. Bernal: Univ. Nacional de Quilmes, 2007.

SMITH, Adam. Investigação sobre a natureza e as causas da riqueza das nações. $3^{a}$ edição. São Paulo: Abril Cultural, 1984. 
Investigação sobre a natureza e as causas da riqueza das nações. $3^{a}$ edição. São Paulo: Nova Cultural, 1988.

STOCZKOWSKI, Wiktor. Anthropologies rédemptrices. Le monde selon Lévi-Strauss [Antropologias redentoras. O mundo segundo Lévi-Strauss]. Paris: Hermann Éditeurs, 2008.

VAINFAS, Ronaldo (org.). Dicionário do Brasil imperial. Rio de Janeiro: Objetiva, 2002. 